\title{
Optimized Matching Lift Unit Transmission Ratio of Engine Driven Ducted Fan
}

\author{
Senlin Xiao , Hongxin Qiao , Guanxiong Xu , Guailin Luo , Chao Ma , Zhiyong Guo and Depeng Zhang \\ Kuang-chi Institute of Advanced Technology, No. 9 Gaoxin Middle $1^{\text {st }}$ Road, 518100 Shenzhen, China
}

\begin{abstract}
As a kind of VTOL technology, ducted fan is not only used by many kinds of aircrafts, but also one of the trends of the future aircraft lift system, and attracts more and more attention. For an engine driven ducted fan lift unit, involving the engine and ducted fan matching problem, the form of transmission and transmission ratio are the key design parameters. In order to design and develop a ducted fan aircraft reasonably, a thrust test platform was set up to connect the engine with the ducted fan through the belt driving. The matching relationship between the engine and the transmission system was experimentally studied and the optimal transmission ratio was determined. The results showed that the optimal transmission ratio for the engine 1 is $2.2: 1$, and for the engine 2 , the optimal transmission ratio should be 2.95:1 based on the current ducted and movable blade aerofoil design. At this time, the lift will exceed $130 \mathrm{~kg} \bullet f$, meeting the aircraft's original design requirements.
\end{abstract}

\section{Introduction}

The traditional fixed-wing aircraft, which requires high starting conditions and poor manoeuvrability, however ducted fan-powered aircraft has high-speed flying and hovering ability, as well as VTOL (Vertical Take-off and Landing) capability, less affected by the environment and good manoeuvrability, and has a wide range of applications, has become one of the important research hot spots ${ }^{[1-4]}$. Since the 1960 s of the last century, ducted fan powered aircraft such as Airgeep, Doak 16, Cypher and AirMule have been released ${ }^{[1,5]}$. The latest news shows that Jetpack manufactured by Martin Jetpack in New Zealand is an aircraft with twin ducked fan as a lifting unit (see Figure 1) ${ }^{[6]}$.

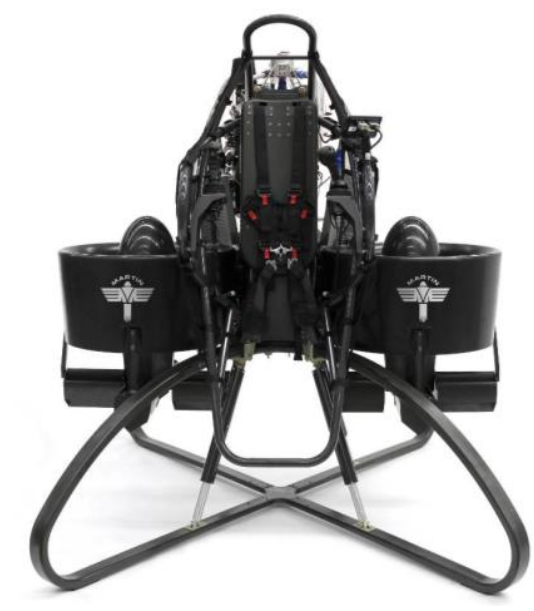

Figure 1. The latest version of Jetpack.
Early NASA studied the ducted fan aerodynamic characteristics and flow characteristics through the wind tunnel test. Ohanian $\mathrm{III}^{[3]}$ investigated the potential of using Synthetic Jet Actuators (SJA) to control the flight stability of ducted fans. Will ${ }^{[4]}$ experimentally studied the aerodynamic characteristics of various ducted lip shapes, including the leading edge radius of the ducted lip and the culvert wall thickness, and found that the smaller leading edge radius favours the stability under take-off and crosswind conditions, whereas the larger leading edge radius enhances the stability under static conditions. Further flow visualization and static pressure measurements revealed that the cause of the above differences was due to the flow separation inside the ducts lip surface. Pflimlin ${ }^{[5]}$ designed an attitude control method based on a linearization of the dynamics model to control the balance stability of hovering of ducted fan micro UAVs in crosswind.

The lift unit formed by the engine-driven ducted fan relates to the match between the engine and the ducted fan, and the form of the transmission and the setting of the transmission ratio are directly related to the design of the aircraft and the performance of the aircraft. In this paper, a thrust test platform was set up which connected the engine with the ducted fan through the belt drive. The aerodynamic characteristics of the ducted fan in the hovering state were measured. Specifically, the relationship between the ducted fan suction power, the fan speed and the thrust generated by the ducted fan was measured. Then, a design idea of lift unit transmission system for engine-driven ducted fan was established and the transmission ratio was optimized, and evaluated the 
applicability of ducted fan system as the lift system of aircraft.

\section{Thrust test platform}

Thrust test bench, shown in Figure 2, length $\times$ width $\times$ height is $1900 \mathrm{~mm} \times 1900 \mathrm{~mm} \times 2334 \mathrm{~mm}$, which including ducted fan, power systems, thrust gantry, transmission systems and sensors. Ducted fan is fixed on the mobile frame of thrust gantry. The power system is located under the ducted fan, fixed on the fixed frame of thrust gantry, connected to the fan shaft through the transmission system. The transmission system mainly includes two synchronous belt pulleys, one timing belt, two belt tension pulleys, and one transmission shaft. The changes of the transmission ratio are realized by changing synchronous pulleys with different numbers of teeth, and meanwhile the belt tensioning pulley is used to adjust the belt preload. The entire transmission system is shown in Figure 3. The mobile frame is connected with the heavyduty linear guide on the fixed frame through the precision sliding block, so that the mobile frame can only move back and forth along the axial direction of the guide rail. Fixed frame is fixed to the ground, once the ducted fan is running, the thrust will be generated which causing the mobile frame to move along the guide rail, and the thrust will be measured by the thrust sensor.

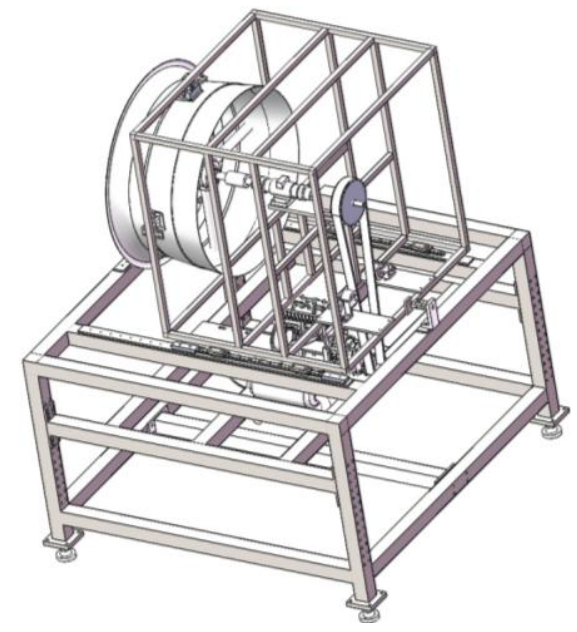

Figure 2. Thrust test bench schematics.

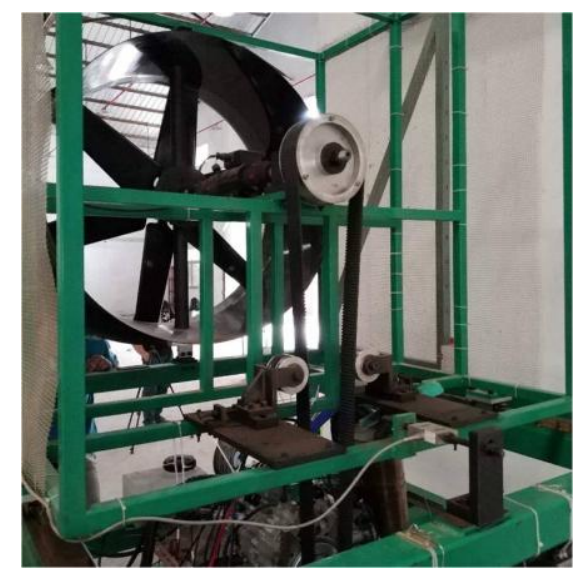

Figure 3. Transmission system diagram.

\section{Test results and analyses}

\subsection{Engine performance}

The performance of engine 1 and engine 2 is shown in Figure 1 and Figure 2. Obviously, the engine 2 can run at a higher speed range. The match between the engine and the ducted fan must consider the performance characteristics of different engines.

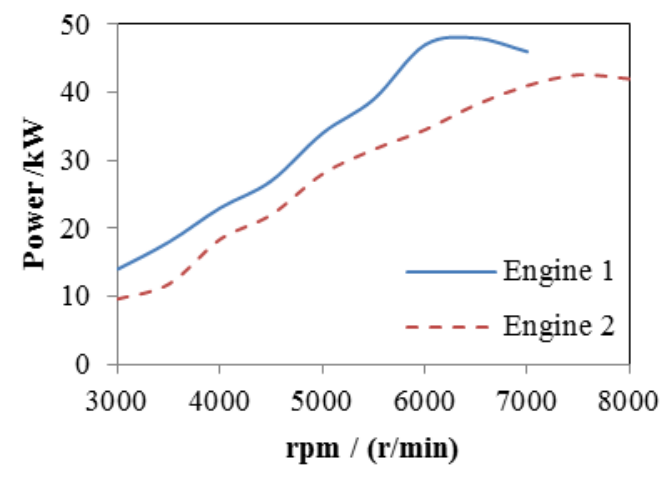

Figure 4. Power of engine 1 and engine 2.

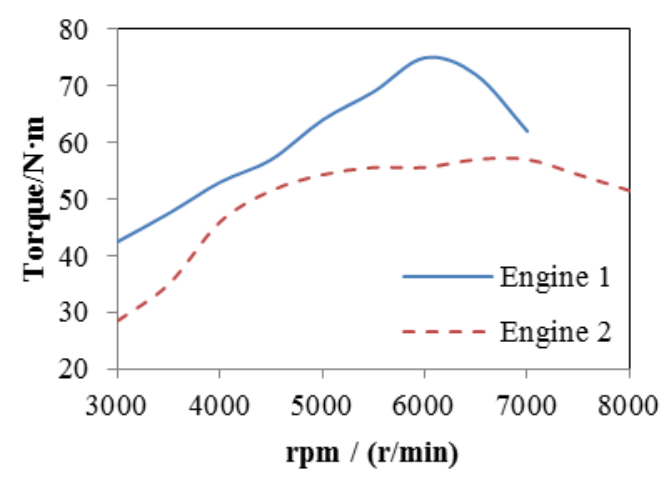

Figure 5. Torque of engine 1 and engine 2.

\subsection{Matching analysis}

In order to avoid the impacts of environmental conditions on the test results, ducted fan absorption power $P_{\mathrm{e}}$ was calculated according to equation 1 , the measured data during the test included the fan speed $n_{f}$ and torque $M_{e}$. Ducted fan thrust $F_{0}$ was calculated by Equation 2, where $T$ was measured ambient temperature, $T_{0}, p_{0}$ was the international standard atmospheric temperature and pressure; $T, p$ was the measured ambient air temperature and pressure; $F$ was the measured thrust.

$$
\begin{gathered}
P_{\mathrm{e}}=2 \pi n_{f} M_{e} / 60 \\
F_{0}=\left(T / T_{0}\right)\left(p_{0} / p\right) F
\end{gathered}
$$

The design of the transmission relationship is based on the structural design. At the same time, the form and matching of the transmission system directly affect the aerodynamic load distribution of the ducted fan. Furthermore, the distribution of the aerodynamic load will in turn affect the structural design. The matching 
principle of the transmission system is that on one hand, the engine runs a suitable target operating point, and gives full play to the performance of the engine. On the other hand, the ducted fan runs at the best working point, and provides suitable lift for the entire lifting unit. And the thrust-to-weight ratio of the entire lift unit meets the design goals.

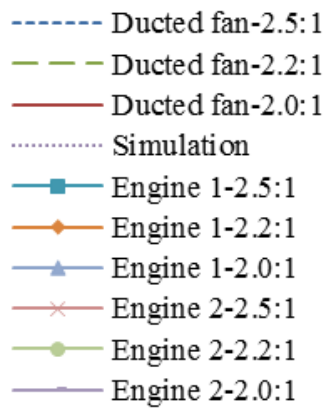

Figure 6. Illustration of each figure.

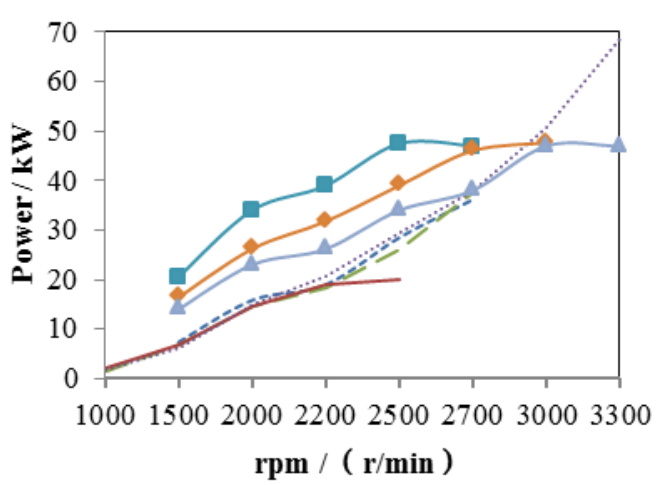

Figure 7. The relationship between power and speed when the engine 1 matches the ducted fan.

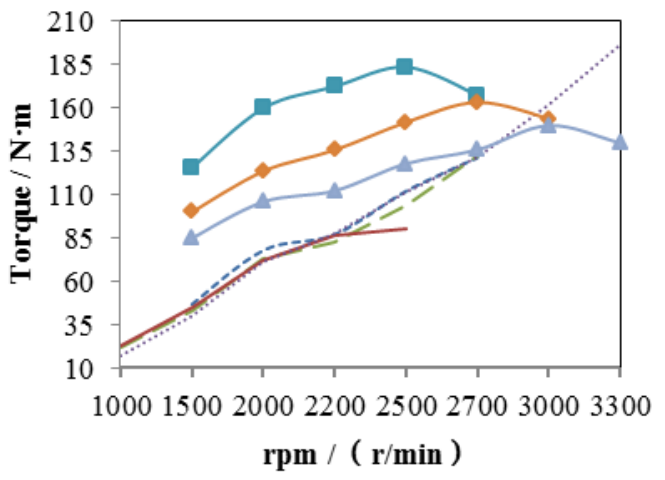

Figure 8. The relationship between torque and speed when the engine 1 matches the ducted fan.

Figure 7 and Figure 8 are the relationships between power and speed, torque and speed when engine 1 matches the ducted fan. The figure gives the engine speed characteristics when the gear ratios are 2.0:1, 2.2:1 and 2.5:1, respectively. For comparative analysis, Figure 6 shows the legend in the following figures. At the same time, the figure shows the aerodynamic characteristics calculated by CFD as a reference and characteristics tested by thrust test bench. The test verified the rationality and reliability of the simulation and confirmed that the simulation data can be used to design and optimize the ducted fan. Note that the test data is represented by ducted fan-2.5:1, ducted fan-2.2:1, and ducted fan-2.0:1 respectively in figures. In addition, the influence law of the propeller blade pitch angle on the thrust was studied experimentally. For current duct and blade aerofoil designs, the optimal blade pitch angle is $30^{\circ}$. In the next study, the pitch angle remained unchanged, so the ducted fan's thrust characteristics and the speed formed a fixed relationship. Obviously, it can be found that the matching of the engine 1 and the ducted fan is most reasonable when the transmission ratio is 2.2:1. At this ratio, the ducted fan can operate at higher speeds with sufficient power and torque. The significant advantage is that the performance of the engine can be effectively utilized while the ducted fan's thrust can be increased accordingly.

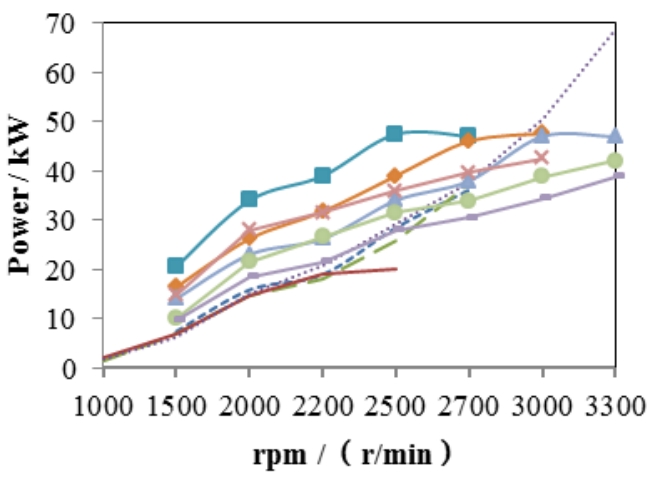

Figure 9. The relationship between power and speed when the engine 2 matches the ducted fan.

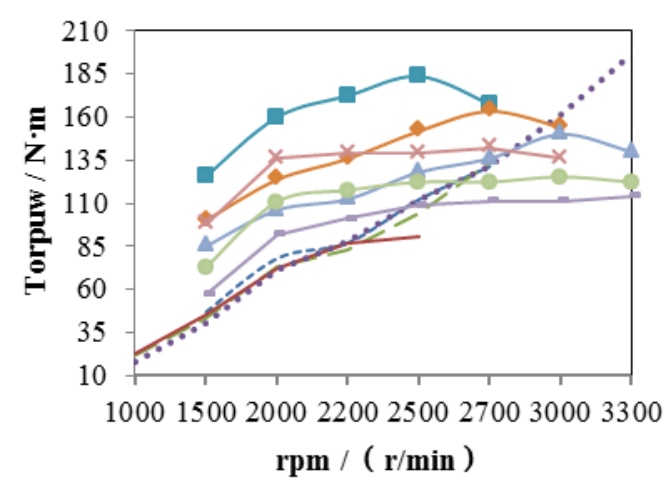

Figure 10. The relationship between torque and speed when the engine 2 matches the ducted fan.

Figure 9 and Figure 10 are the relationships between power and speed, torque and speed when engine 2 matches the ducted fan. The figure gives the speed characteristics of engine 2 when the gear ratios are 2.0:1, $2.2: 1$ and $2.5: 1$, respectively. When the transmission ratio was $2.5: 1$, the fan speed was $2500 \mathrm{r} / \mathrm{min}$, output of engine 2 was $36 \mathrm{~kW}$, and the measured duct fan absorption power was $28.477 \mathrm{~kW}$. Therefore the power exceeded the demand of about $26.418 \%$, and the torque exceeded the demand of about $15.970 \%$. When the transmission ratio was $2.2: 1$, the fan speed was $2500 \mathrm{r} / \mathrm{min}$, output of engine 2 was $31.6 \mathrm{~kW}$, and the measured duct fan absorption 
power was $25.95 \mathrm{~kW}$. Therefore the power exceeded the demand of about $21.773 \%$, and the torque exceeded the demand of about $17.615 \%$. However, the speed of ducted fan couldn't exceed $2700 \mathrm{r} / \mathrm{min}$ because of lack of the efficient torque for the output of gear. When the transmission ratio was $2.0: 1$, the transmission output of torque was less than the ducted fan torque. In other words, the transmission ratio is invalid for the current construction. Taking into account the transmission efficiency and friction loss of whole system, the output torque of transmission must greater than the torque of ducted fan.

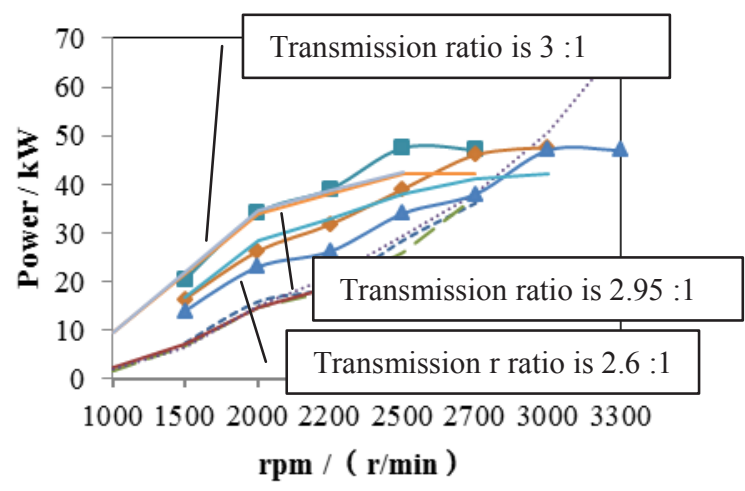

Figure 11. The relationship between power and speed when the engine 2 matches the ducted fan by increasing transmission ratio.

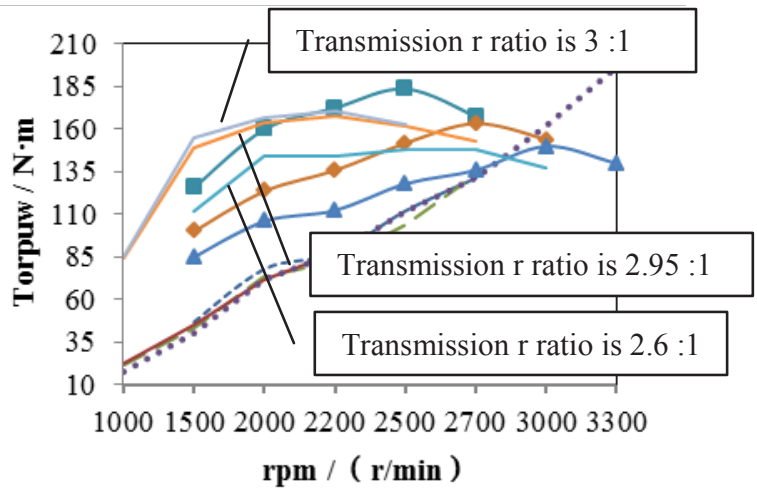

Figure 12. The relationship between torque and speed when the engine 2 matches the ducted fan by increasing transmission ratio.

Matching engine and ducted fan related to the performance of various subsystems, including the engine speed characteristics, engine load characteristics, ducted fan speed thrust characteristics, speed torque characteristics, different blade pitch angle characteristics, through constant optimization iteration of each parameter, it is necessary to design the working point and precise design of transmission ratio, which can significantly improve the overall performance of the aircraft. From the above analysis, we found that we can further increase the transmission ratio to match the engine and ducted fan. Figure 11 and 12 are the relationships between power and speed, torque and speed when engine 2 matches the ducted fan. Due to the maximum speed of engine 2 is $8000 \mathrm{r} / \mathrm{min}$, referring to the power and torque characteristics of engine 1 , it is known that the transmission ratio is 2.6:1, and the ducted fan speed can reach $2500 \mathrm{r} / \mathrm{min}$, the lift can exceed $100 \mathrm{~kg} \bullet \mathrm{f}$. If the transmission ratio is $3: 1$ or $2.95: 1$, the fan speed can up to $2600 \mathrm{r} / \mathrm{min}$ at least. And changing the gear ratio makes it possible to reach to $2700 \mathrm{r} / \mathrm{min}$ for ducted fan speed. At this point, the engine delivered $152.545 \mathrm{~N} \cdot \mathrm{m}$ with a measured duct fan torque of $131.4 \mathrm{~N} \cdot \mathrm{m}$ and the torque exceeded the demand of about $16.092 \%$. Note that, when the ducted fan speed is $2700 \mathrm{r} / \mathrm{min}$, the lift force will exceed $130 \mathrm{~kg} \bullet \mathrm{f}$, which meeting the original design requirements of the aircraft. As the transmission ratio changes, the output characteristics of transmission system will be changed accordingly. Because of the engine speed characteristics, the speed couldn't exceed the $2700 \mathrm{r} / \mathrm{min}$ for engine 2 when the transmission ratio was 3.0:1, which was shown in Figure 11 and Figure 12. The only choice for transmission ratio is $2.95: 1$ if the lift force needed to exceed $130 \mathrm{~kg} \bullet \mathrm{f}$.

\section{Conclusions}

In order to measure the thrust characteristics, thrust test bench was designed and developed, and the key parameters of the lift unit were determined through experimental research, which will provide guidance for further research and development of new aircraft. Based on the above research, there are following important conclusions:

(1) On one hand based on the maximum performance of the engine, on the other hand based on further increasing ducted fan speed to increase the lift, after comparing the three gear ratios, it is found that the optimal transmission ratio is $2.2: 1$ for engine 1 .

(2) The test found that when the ducted fan speed is $2700 \mathrm{r} / \mathrm{min}$, the resulting lift will exceed $130 \mathrm{~kg} \bullet \mathrm{f}$, meeting the initial design requirements of the aircraft. Therefore, when matching engine 2 to a ducted fan, the best transmission ratio should be $2.95: 1$ and the pitch angle is $30^{\circ}$.

\section{References}

1. Yuanwei Li, Boqi Xi, Guoxing Yi, Changhong Wang. Journal of Harbin Institute of Technology 42, 5 (2010)

2. Kai Liu, Fuchen Ye. Advances in Aeronautical Science and Engineering 6, 2 (2015)

3. Ohanian III. Ducted Fan Aerodynamics and Modeling, with Applications of Steady and Synthetic Jet Flow Control. (Virginia Polytechnic Institute and State University, United State, 2011)

4. Will E G. Effects of duct lip shaping and various control devices on the hover and forward flight performance of ducted fan UAVs. (Virginia Polytechnic Institute and State University, United State, 2005)

5. Pflimlin J M, Binetti $P$, Soueres $P$, Hamel T., Trouchet D. Modeling and attitude control analysis of a ducted-fan micro aerial vehicle. Control Engineering Practice 18, 3(2010)

6. http://martinjetpack.com/ 